\title{
Gastrointestinal bleeding in a young man: Think outside the box
}

\author{
Hemanta K. Nayak ${ }^{1}$ - Abhai Verma ${ }^{1}$ - Uday C. Ghoshal ${ }^{1}$
}

Published online: 14 May 2015

(C) Indian Society of Gastroenterology 2015

Hereditary hemorrhagic telangiectasia (HHT) is a rare autosomal dominant disorder of the fibrovascular tissue, characterized by the triad of mucocutaneous telangiectasia, recurrent epistaxis and familial occurrence. Clinical manifestation may vary from recurrent epistaxis to overt gastrointestinal (GI) bleeding from telangiectatic lesions in mucocutaneous surfaces. Esophagogastroduodenoscopy in a young man with hematemesis and melena of short duration coupled with history of recurrent epistaxis since childhood and a family history of similar symptoms in his elder brother revealed multiple telangiectasia in the fundus and body of the stomach (Fig. 1a). Capsule enteroscopy revealed hookworms in the small intestine as an incidental finding (Fig. 1b). The clinical manifestations of HHT are variable and age dependent and treatment is individualized [1]. Capsule endoscopy can evaluate the entire small bowel to detect additional telangiectasia, but hookworm infestation was an important additional finding in this patient [2]. Hookworm infestation is known to be an etiological factor of both obscure occult and overt GI bleed in tropical countries like India, and this patient underscores the importance of incidental parasitosis in contributing to GI bleeding in an individual with another overt cause for bleeding.
Fig. 1 a

Esophagogastroduodenoscopy revealed multiple telangiectasia in the fundus and body of the stomach. b Capsule enteroscopy revealed sucking hookworm

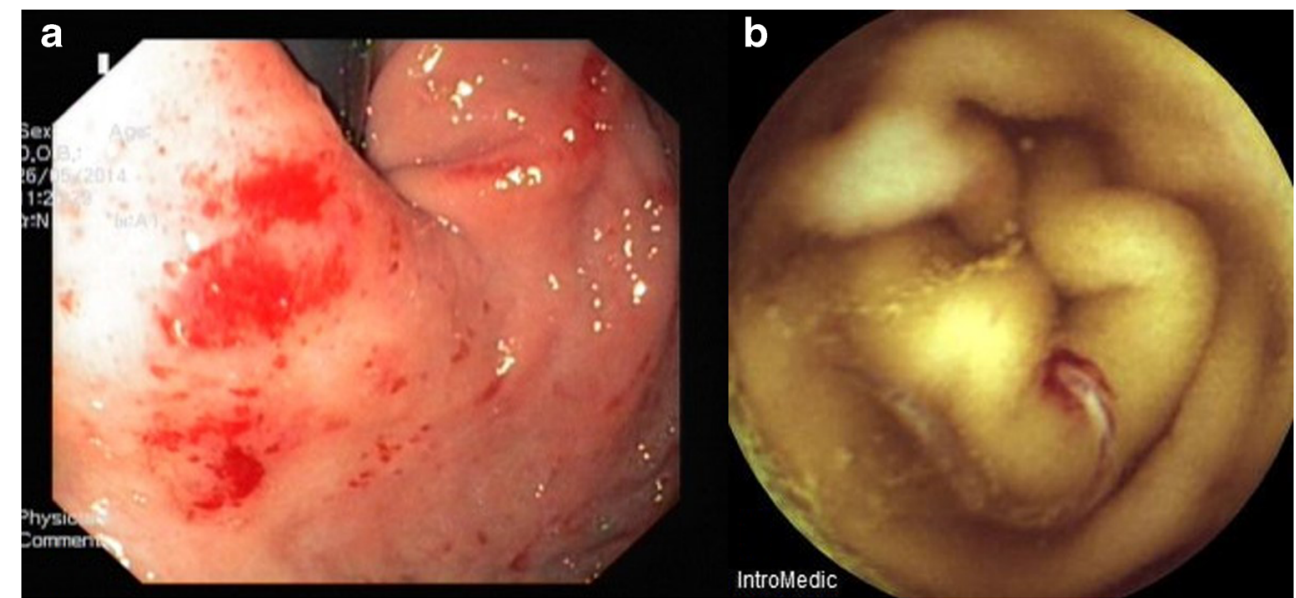

Uday C. Ghoshal

udayghoshal@yahoo.co.in

1 Department of Gastroenterology, Sanjay Gandhi Postgraduate Institute of Medical Sciences, Lucknow 226 014, India

\section{References}

1. Garzon MC, Huang JT, Enjolras O, Frieden IJ. Vascular malformations. Part II: associated syndromes. J Am Acad Dermatol. 2007;56:541-64.

2. Morales CP, Ferrer G, Zuckerman MJ. Hookworm detected by capsule endoscopy. Gastrointest Endosc. 2005;62: $782-3$. 